莱

\title{
FORMAS ESPACIAIS SIMBÓLICAS QUE REMEMORAM HISTÓRIAS APAGADAS - MARCAS DA TERRITORIALIDADE JUDAICA EM NILÓPOLIS (RJ)
}

\section{- ENDERSON ALBUQUERQUE ${ }^{1}$}

Doutor em Geografia pelo PPGEO/UERJ. E-mail: endersonalbuquerque@yahoo.com.br

\section{- MIGUEL ANGELO RIBEIRO²}

Professor Associado do IGEOG/PPGEO-UERJ. E-mail: mamikisi@gmail.com

Recebido em: 10/11/2020

Aprovado em: 14/12/2020

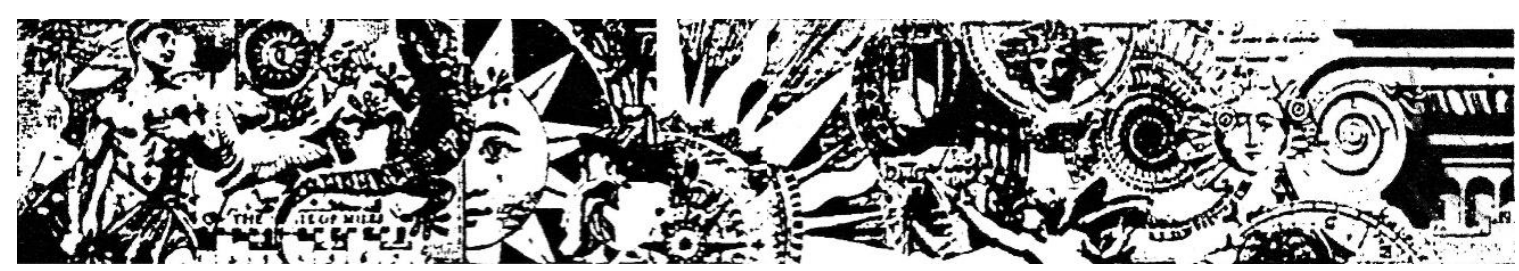

Resumo: A partir de 1928, judeus de origem polonesa e russa migraram para o município de Nilópolis, localizado na Baixada Fluminense, Região Metropolitana do Rio de Janeiro. Em razão de sua cultura, esses imigrantes construíram espaços sociais e religiosos para manter suas tradições. Desse modo, nosso objetivo consiste em analisar a construção desses espaços, considerando sua relação com os moradores. Posto isso, 0 artigo apontou que esses espaços, embora tenham sido marcas territoriais de relevância social e econômica da presença dessa colônia no passado, atualmente encerram apenas manifestações de natureza memorísticas no espaço nilopolitano.

Palavras-chave: Formas simbólicas espaciais; Baixada Fluminense; Nilópolis; Cultura judaica; Sagrado. 


\title{
SYMBOLIC SPACE FORMS THAT REMEMBER DELETE STORIES - BRANDS OF JUDAIC TERRITORIALITY IN NILÓPOLIS (RJ)
}

\begin{abstract}
FROM 1928, JEWS OF POLISH AND RUSSIAN ORIGIN MIGRATED TO THE MUNICIPALITY OF NILÓPOLIS, LOCATED IN THE BAIXADA FLUMINENSE, METROPOLITAN REGION OF RIO DE JANEIRO. DUE TO THEIR CULTURE, THESE IMMIGRANTS NEEDED TO BUILD SOCIAL AND RELIGIOUS SPACES TO MAINTAIN THEIR TRADITIONS. THUS, OUR GOAL IS TO ANALYZE THE CONSTRUCTION OF THESE SPACES CONSIDERING THEIR RELATIONSHIP WITH RESIDENTS. THAT SAID, THE ARTICLE POINTED OUT THAT THESE SPACES, ALTHOUGH THEY WERE TERRITORIAL MARKS OF SOCIAL AND ECONOMIC RELEVANCE OF THE PRESENCE OF THIS COLONY IN THE PAST, CURRENTLY CONTAIN MANIFESTATIONS OF A MEMORABLE NATURE ONLY IN THE NILOPOLITAN SPACE
\end{abstract}

KEYWORDS: SPATIAL SYMBOLIC FORMS; BAIXADA FLUMINENSE; NILÓPOLIS; JEWISH CULTURE; SACRED.

\section{FORMAS ESPACIALES SIMBÓLICAS QUE RECUERDAN BORRAR HISTORIAS: MARCAS DE TERRITORIALIDAD JUDAICA EN NILÓPOLIS (RJ)}

RESUMEN: A PARTIR DE 1928, JUDÍOS DE ORIGEN POLACO Y RUSO EMIGRARON AL MUNICIPIO DE NILÓPOLIS, UBICADO EN LA BAIXADA FLUMINENSE, REGIÓN METROPOLITANA DE RÍO DE JANEIRO. DEBIDO A SU CULTURA, ESTOS INMIGRANTES CONSTRUYERON ESPACIOS SOCIALES Y RELIGIOSOS PARA MANTENER SUS TRADICIONES. ASÍ, NUESTRO OBJETIVO ES ANALIZAR LA CONSTRUCCIÓN DE ESTOS ESPACIOS, CONSIDERANDO SU RELACIÓN CON LOS VECINOS. DICHO ESTO, EL ARTÍCULO SEÑALÓ QUE ESTOS ESPACIOS, SI BIEN FUERON MARCAS TERRITORIALES DE RELEVANCIA SOCIAL Y ECONÓMICA DE LA PRESENCIA DE ESTA COLONIA EN EL PASADO, EN LA ACTUALIDAD SOLO CONTIENEN MANIFESTACIONES DE CARÁCTER MEMORABLE EN EL ESPACIO NILOPOLITANO.

PALABRAS CLAVE: FORMAS SIMBÓLICAS ESPACIALES; BAIXADA FLUMINENSE; NILÓPOLIS; CULTURA JUDÍA; SAGRADO.

\section{Introdução}

Localizado na Baixada Fluminense, o município de Nilópolis teve sua gênese a partir de loteamentos iniciados em 1914. Em razão de sua geografia periférica, a localidade atraiu população de baixo status social oriunda de estados nordestinos, Espírito Santo e Minas Gerais em um primeiro momento (ALBUQUERQUE, 2017). A partir de 1920, o município passou a presenciar a chegada de migrantes libaneses e, na segunda metade desta década, de judeus (LONDON, 1999; PERES, 2015).

Tendo em vista a revisão de literatura e pesquisas a periódicos e trabalhos acadêmicos, o objetivo geral deste artigo incide em investigar como esse grupo, a partir de suas práticas socioculturais, estruturou-se territorialmente em Nilópolis e as 
repercussões materiais e imateriais oriundas desse processo para a dinâmica local. Essa análise será empreendida a partir do conceito da geografia de formas simbólicas espaciais, considerando as edificações semitas na localidade. Desse modo, o conceito em questão emprega geograficidade à abordagem do tema. Assim sendo, o recorte espacial deste artigo é o município de Nilópolis e o recorte temporal selecionado compreende os anos de 1928, quando a comunidade semita iniciou sua migração para Nilópolis, até 2020, ano de escrita deste artigo.

Para responder essas questões e atingir os objetivos propostos, este artigo se divide em duas partes. Na primeira, objetivamos estabelecer a evolução jurídica e socioeconômica do espaço nilopolitano, desde subdistrito até sua emancipação. A elevação de Nilópolis a município se deu em estreita ligação com a refuncionalização de sua dinâmica econômica. Essa alteração, por sua vez, teve como um de seus protagonistas o grupo de imigrantes judeus que se estabeleceu na localidade na década anterior. A importância desse grupo para o desenvolvimento socioeconômico de Nilópolis constitui o cerne dessa primeira seção. Além da produção material da cidade, os judeus produziram formas simbólicas espaciais na paisagem local, as quais são analisadas na segunda parte do artigo.

\section{A formação da colônia judaica em Nilópolis}

O espaço nilopolitano encerrou, ainda no final do século XIX, sua principal atividade agrícola, a cana de açúcar. Esse processo, aliado à maior proximidade com o núcleo metropolitano, conforme menciona Oliveira (2011), antecipou a transformação do uso de suas terras. Já em Nova Iguaçu, o uso agrícola da terra perdurou até meados do século XX com a citricultura. Desse modo, a partir de 1940 a questão da terra ganhou extrema relevância em Nilópolis. Nesse período "não havia mais terras disponíveis para loteamento na cidade, restando apenas a ocupação dos loteamentos já comercializados" (SIMÕES, 2008, p. 92). O distinto uso da terra entre a sede municipal iguaçuana e seus distritos que apresentavam maior grau de urbanização passou a gerar disputas.

De acordo com Simões (2004, p. 53), a disputa fundiária entre agricultores e promotores imobiliários seria decidida pelo início da Segunda Guerra Mundial. Esse evento histórico diminuiu sensivelmente o poder político das elites ligadas à citricultura em virtude da queda no valor de seu produto e, assim, “o fim do projeto agrário abre espaço para o projeto urbano e as forças locais dos distritos ganham novo fôlego para 
retomar a luta pela emancipação”. Nessa configuração histórica, fundiária e política ocorreu a emancipação de Nilópolis. No dia 20 de junho de 1947 foi promulgado o artigo $6^{\circ}$ da Lei Estadual $N^{\circ} 67$, de autoria do Deputado Andrade Figueira. A emancipação política foi efetivada em 21 de agosto de 1947, assim como a do município de São João de Meriti, este último desvinculado de Duque de Caxias.

Desse modo, as atividades comerciais em Nilópolis, em paralelo à diminuição do poder econômico e político da elite iguaçuana ligada à citricultura, possibilitaram maior força política aos promotores imobiliários e agentes da burguesia comercial e industrial nascentes na localidade. Dentre esse grupo comercial que refuncionalizou o espaço econômico nilopolitano estiveram os judeus, que começaram a chegar à localidade no final dos anos 1920. Nesse período, Nilópolis ainda era distrito de Nova Iguaçu. A parada de trem inaugurada em 1914 ajudou sobremaneira a alterar a dinâmica econômica local. Sobre este processo, Segadas Soares (1962, p. 172) identifica que

a constituição espontânea de núcleos em torno das estações ferroviárias é a forma mais antiga pela qual começou a se realizar a dilatação do espaço urbano do Rio de Janeiro em direção à baixada. Ao lado de cada estação, casas iam-se dispondo espontaneamente, algumas lojas surgiam, uma pracinha tomava forma e aos poucos iam crescendo esses aglomerados que, de início, tinham forma longitudinal, alinhando-se às margens dos trilhos, para só depois crescerem num sentido transversal à linha férrea.

A comunidade judaica foi de notória relevância para o processo mencionado pela autora. Considerando o espaço nilopolitano, os semitas intensificaram o adensamento populacional ao mesmo tempo em que promoveram o desenvolvimento de novas atividades econômicas na localidade. Baseado no historiador Nachman Falbel, Soares (2014) indica a existência de quatro ondas de imigração desse grupo étnico provenientes da Europa. A primeira de 1904 a 1914, a segunda entre 1914 e 1933, a terceira abrangendo o período de 1933 a 1945, em razão da perseguição na Europa, e a quarta onda de 1945 a 1957, no período pós-segunda Guerra Mundial. O grupo inicial que se instalou em Nilópolis adveio da segunda onda aludida pelo autor.

Entretanto, para muitos, Nilópolis não foi a primeira casa em solo fluminense. A Praça Onze, localizada na área central do Rio de Janeiro, concentrou expressiva população israelita, de forma que 
ali se localizavam suas casas comerciais, oficinas e instituições religiosas, filantrópicas, culturais, sociais, recreativas e ideológicas. Os proprietários de lojas e de pequenas manufaturas em geral residiam no segundo andar dos sobrados, enquanto os trabalhadores muito pobres moravam em cortiços [...] Estes judeus estavam acima da linha da miséria típica dos moradores dos cortiços, mas, ou eram pobres bastante para não poderem morar em locais com melhores condições urbanas, ou por não quererem abandonar a convivência com a vizinhança (EARP; FRIDMAN, 2003, p. 65).

A escritora Esther London (1999), judia-polonesa que se erradicou em Nilópolis em 1939, agregando "pesquisa e lembranças dos anos vividos em Nilópolis", escreveu o livro Vivência Judaica em Nilópolis. Para ela, a partir da inauguração da parada de trem em Nilópolis no ano de 1914, os semitas que aportavam na cidade do Rio de Janeiro "passaram a ter mais uma opção de vida ao lado dos generosos trilhos da Central do Brasil: Nilópolis. Mas Nilópolis não foi apenas uma réplica da Praça Onze [...] Era uma cidadezinha onde os judeus gostavam de morar e se sentiam em casa” (LONDON, 1999, 40). Ainda no início de sua urbanização, Nilópolis apresentava características eminentemente rurais, de modo que alguns judeus residentes na referida localidade carioca passavam "uns dias de férias em Nilópolis" (RIBEIRO, 2008, p. 243). Mery Baran, em seu relato ao documentário Novos Lares - A História dos judeus em Nilópolis, lembrou a impressão de sua mãe ao chegar à localidade: "ela ficou muito decepcionada quando chegou ao Porto do Rio, que depois ela veio pra Nilópolis. Nilópolis naquela época era uma cidade sem luz, era uma cidade, realmente quase que rural eu diria, era roça. Eu me lembro de boiada passando na rua" (VIEIRA, 2009).

Considerando a atual configuração territorial da Região Metropolitana do Rio de Janeiro e da Baixada Fluminense, conforme alude a figura 1, Nilópolis é a primeira parada de trem após a cidade do Rio de Janeiro e, em razão do preço dos lotes e de suas dimensões, permitia a construção de moradia mais digna que os cortiços da Praça Onze, já densamente ocupados. 


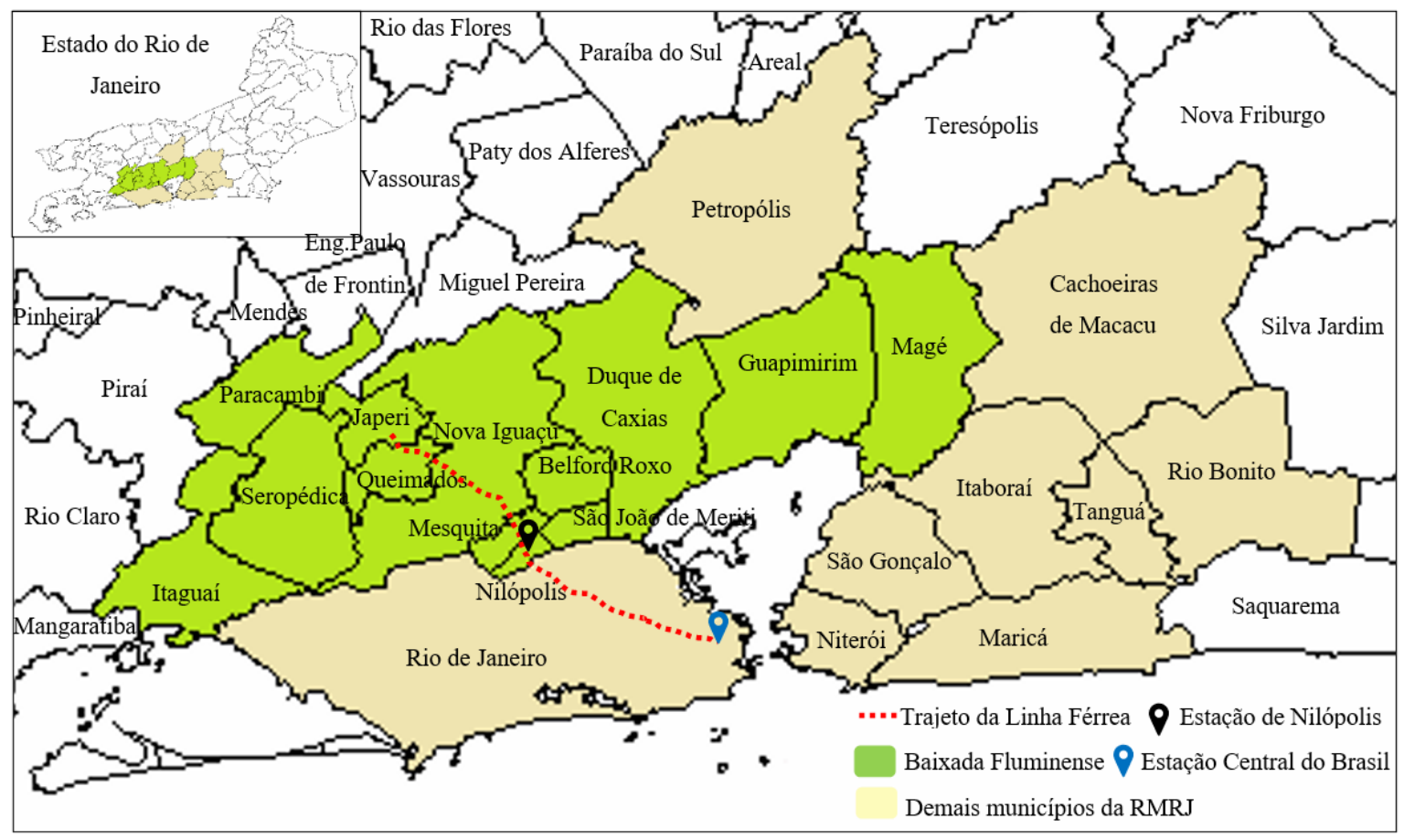

Figura 1: Trajeto da linha férrea sentido Central do Brasil-Japeri Fonte: Elaborado pelos autores (2020)

London (1999, p. 105) compilou depoimentos dos primeiros judeus que se fixaram na cidade baixadiana e, em relação a esse processo, Frida Buksman relatou que

os anúncios da venda de terrenos em Nilópolis, por preços módicos e a prazo, atraíram muitos recém-chegados imigrantes judeus, como meu pai. Com a ajuda das sociedades beneficentes e com um empréstimo da "Lai e Spar Casse", meu pai, foi levado para Nilópolis por um conhecido que achou que ali ele poderia realizar o seu sonho: construir um teto sobre a cabeça. Comprou um lote de terreno e como de profissão era carpinteiro, arrumou dois ajudantes e em pouco tempo nossa casa estava pronta. Eu e minha mãe ficamos felicíssimas. Saímos do cortiço da Praça Onze para morar mais humanamente em Nilópolis, que já tinha muitos habitantes judeus.

Judeus oriundos da terceira onda (1933-1945), período no qual o antissemitismo grassou na Europa, também se destinaram a Nilópolis. Sobre essa conjuntura, Rachel Morgenstern relatou que "na Polônia a crise era constante e o medo do nazismo crescente apavorava os judeus. Com dinheiro no bolso e endereço decorado, chegamos ao cais do porto do Rio de Janeiro, onde nossos tios nos esperavam. Fomos direto para Nilópolis" (LONDON, 1999, p. 107).

A integração dessa comunidade estrangeira à comunidade local se efetivou sem problemas de ordem xenofóbicas. Excetuando-se algumas provocações de grupos integralistas e as campanhas difamatórias, esse agrupamento étnico passou a estabelecer 
relações de natureza simbólica e material com Nilópolis, passando a contabilizar cerca de 300 famílias na cidade. Quanto à sua origem, além de judeus oriundos de países como a Hungria, Áustria, Romênia, Ucrânia e Alemanha, a comunidade hebraica local "foi formada em grande parte por imigrantes judeus de origem polonesa e russa, pertencentes ao grupo dos asquenazitas, maior contingente de imigrantes judeus para terras brasileiras" (RAPOSO, 2014, p. 29).

Para Claval (2012, p. 105), "ao se congregar em torno de preceitos comuns, os grupos abolem as distâncias psicológicas que existem entre os seus membros, o que lhes permite triunfar sobre a dispersão associada frequentemente às necessidades da vida”. Desse modo, considerando a natureza simbólica dessa relação, essa população que necessitou emigrar por imposições alheias à sua vontade pôde manifestar livremente sua religião, língua e tradições em Nilópolis e, por esse motivo, recriaram na cidade baixadiana a atmosfera de seus vilarejos de origem. As notícias que chegavam à Polônia referindo-se a Nilópolis enfatizavam que "lá, diziam muitos, tudo é ídiche. Quem mora em Nilópolis não sente saudades do shtetl na Polônia” (LONDON, 1999, p. 110).

Em ídiche, a palavra shtetl significa cidadezinha, porém, "quando um judeu se refere a um espaço como um shtetl, isso quer dizer que ele está impondo uma conotação emocional, pois esse espaço o faz relembrar de seu lugar de origem” (RAPOSO, 2014, p. 30). Esse sentimento de "sentir-se em casa" também se devia, em larga medida, às estruturas culturais construídas pela comunidade semita, entre as quais constavam, além da Sinagoga e o Cemitério Israelita, fixos sociais analisados neste artigo, uma "escola israelita S. An-Ski e um centro comunitário. Mais tarde uma filial do clube Macabi também se instalaria em Nilópolis" (NOGUEIRA, 2009, p. 190). Desse modo, o centro Israelita "era um teto protetor para todas as faixas etárias da comunidade. Sinagoga para os mais velhos, Clube para a juventude e Escola para as crianças" (LONDON, 1999, p. 59). Cumpre ainda registrar que o primeiro livro em ídiche do Brasil, "Novos Lares", escrito por Adolpho Kischinhevsky em 1932, foi editado e publicado em Nilópolis (SOARES, 2014, p. 69).

Embora no distrito de Olinda houvesse lojas de proprietários hebreus, a coletividade judaica se concentrou na rua então nomeada Lazaro de Almeida, e, pelo fato de os estabelecimentos de propriedade dos semitas ficarem na parte de baixo e as famílias residirem nos sobrados ou nos fundos, esse logradouro ficou conhecido popularmente como a rua dos judeus, pois 
a experiência dos judeus na cidade qualificou essa rua, na qual viviam, moravam, trabalhavam, como ponto de convergência entre os membros da comunidade, atribuindolhe, assim, uma funcionalidade cuja missão era alicerçar a memória coletiva, já que se parecia com uma réplica dos seus antigos povoados europeus, as chamadas "shtetlech" [plural de cidades judaicas] (RAPOSO, 2014, p. 31).

Entretanto, apesar dessa identificação com o espaço e da criação de estruturas e ambientes condizentes com suas práticas religiosas, ao conseguirem melhorias financeiras, os membros da comunidade judaica foram paulatinamente deixando o município. Soares (2014, p. 81) indica que, em virtude do êxodo verificado em Nilópolis, a comunidade local deixou de ter rabino e pessoas contratadas "para oficiar as orações e, não se tinha mais o serviço prestado de nenhum dos três shoichet ${ }^{2}$ que havia na "rua dos judeus". Com isso, tornou-se uma tarefa muito difícil manter a tradição judaica sem todo suporte que antes houvera”.

Os judeus passaram a se dirigir para bairros das zonas sul, norte e oeste da cidade do Rio de Janeiro, sobretudo aqueles de melhor infraestrutura. Alguns, após o fim da perseguição aos judeus, retornaram à Europa, e outros migraram para Israel após a criação desse Estado. O último estabelecimento comercial de um judeu em Nilópolis encerrou suas atividades em 2007.

Judeus ilustres viveram em Nilópolis. Entre eles se destacaram a artista plástica Fayga Ostrower, nascida na Polônia, que passou a residir no município em 1934, e o cantor e ator Agnaldo Rayol, que nasceu no bairro de Bonsucesso, zona norte do Rio de Janeiro, e posteriormente se mudou com a família para a cidade da Baixada Fluminense. Entre os judeus nascidos em Nilópolis, três se destacaram na arte e na sociedade, o médico oncologista Jacob Kilgerman, o estilista Tufi Duek - proprietário das marcas Forum e Triton - e a atriz Tereza Rachel. A atriz está sepultada no Cemitério Israelita de Nilópolis.

Além dessa necrópole semita na qual a ilustre nilopolitana está sepultada, os judeus locais também construíram uma Sinagoga para ser centro de suas atividades religiosas. As duas edificações são exemplos de formas simbólicas espaciais, as quais, entre outros atributos, consistem em "criar 'lugares de memória', cuja função é a de estabelecer ou manter a coesão social em torno de um passado comum” (CORRÊA, 2007, p. 10). A discussão sobre o conceito geográfico de formas simbólicas espaciais contemplando os dois monumentos citados será empreendida na parte seguinte desse trabalho.

\footnotetext{
${ }^{2}$ Especialista que abate galinhas segundo os ritos judaicos. 


\section{Geossímbolos judaicos no espaço/paisagem nilopolitano}

Diferentemente dos libaneses cristãos que chegaram a Nilópolis na década de 1920, os judeus, em virtude das suas práticas religiosas, registraram sua presença no município por meio da construção dos dois fixos religiosos citados. A Sinagoga Tiferet Israel, em português Glória de Israel ou Beleza de Israel, começou a ser construída em 1928, ano da chegada dos primeiros semitas à localidade, e foi inaugurada em 1936.

A partir do início de suas atividades, a Sinagoga passou a centralizar “o exercício da fé judaica, fomentando o equilíbrio espiritual e mantendo viva a tradição através do ensino da torá e hebraico, atividades culturais, fala do idioma iídiche numa religiosidade etnicizada" (SOARES, 2014, p. 78). Em 1984 houve a última celebração no templo (PERES, 2015). Após esse período, o espaço sagrado foi abandonado, conforme atesta a figura 2 .
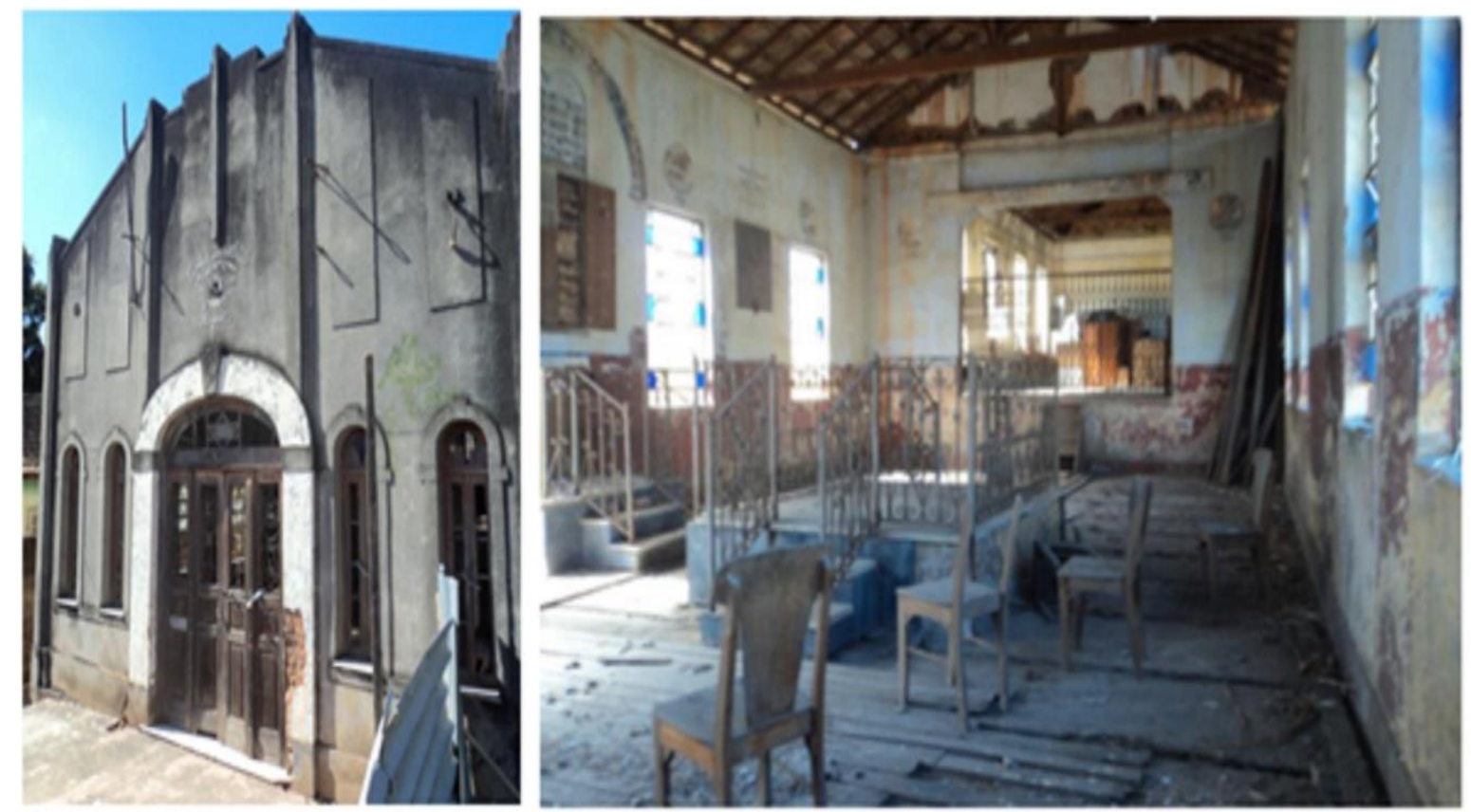

Figura 2: Fachada e interior da Sinagoga Tiferet Israel. Fonte: SOARES (2014, p. 66 e 82). 
Em contraste com o precário estado de conservação da Sinagoga, a necrópole judaica de Nilópolis está em perfeitas condições de conservação (Figura 3). Construído em 1934, O Cemitério Comunal Israelita "foi uma doação do Sr. Motel Zweiter que comprou o terreno com esta finalidade ao lado do cemitério público local $[\ldots .$.$] A iniciativa$ facilitou a vida da comunidade, ou melhor, amenizou os percalços na hora da morte para familiares e amigos" (SOARES, 2014, p. 87).

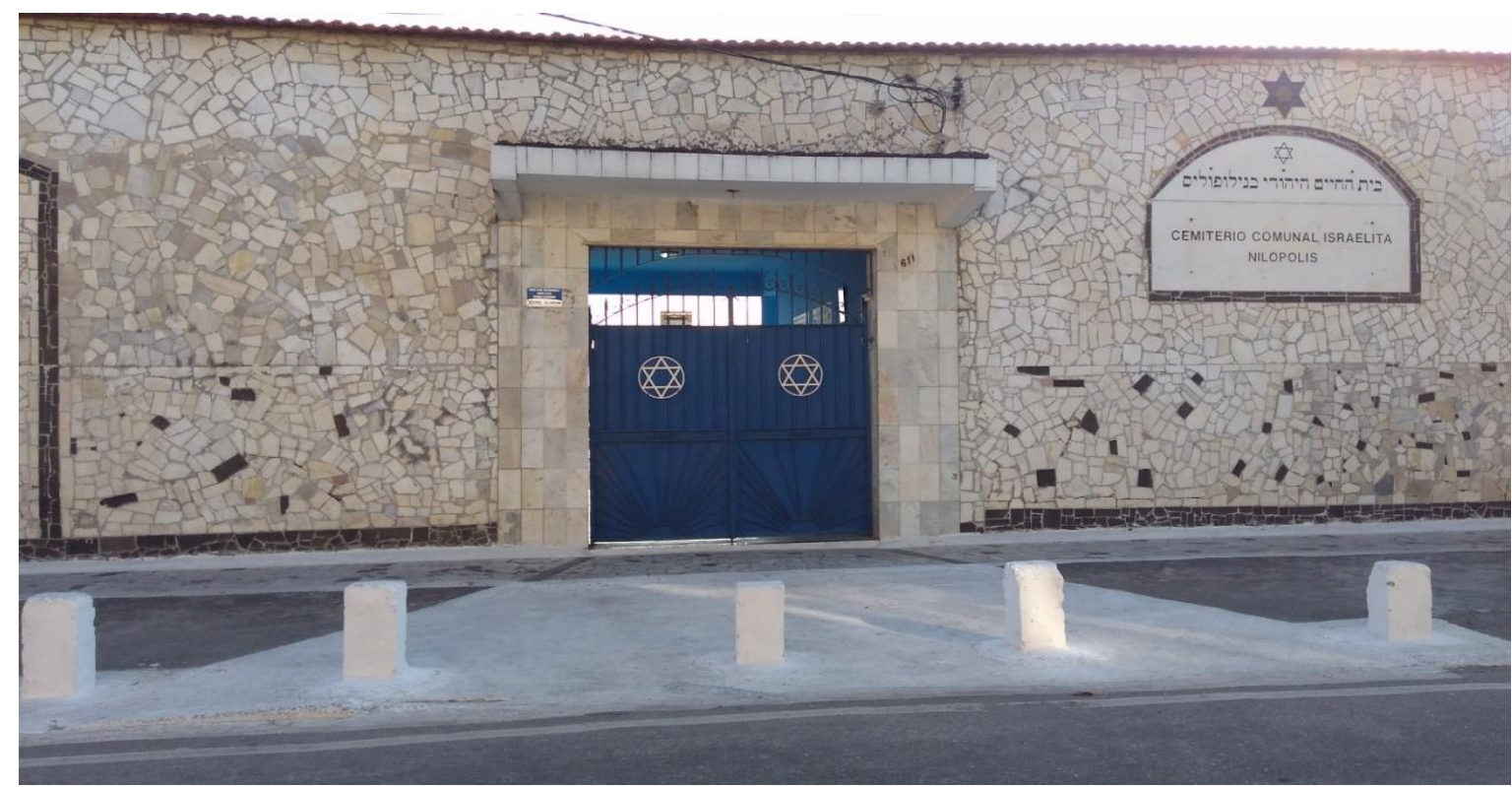

Figura 3: Fachada do Cemitério Comunal Israelita de Nilópolis. Fotografia: Enderson Albuquerque (2019).

Para Claval (2012, p. 103), "os homens inscrevem, nos monumentos que erigem e nas inscrições que fazem aqui e ali, a ordem de significações que os motivam”. Nessa perspectiva, as duas edificações constituem-se em formas simbólicas em grande medida devido aos significados que elas transmitem. Dessa maneira, tanto a Sinagoga quanto o Cemitério compreendem "signos construídos a partir da relação entre as formas, os significantes, e os conceitos, os significados” (CORREAA, 2018, p. 224). Todavia, todo objeto é, em maior ou menor grau, uma forma simbólica, uma vez que ele pode produzir intentos que transcendem sua funcionalidade. Nesse sentido, "um dos desafios da análise geográfica reside em identificar processos visíveis correlatos aos valores simbólicos que presidiriam à estruturação funcional de tais lugares” (MACIEL, 2015, p. 10).

Em termos geográficos, essas construções materiais dotadas de simbolismo se metamorfoseiam em formas simbólicas espaciais 
quando constituídas por fixos e fluxos, isto é, por localizações e itinerários, apresentando, portanto, os atributos primeiros da espacialidade. Palácios, templos, cemitérios, memoriais, obeliscos, estátuas, monumentos em geral, shopping centers, nomes de logradouros públicos, cidades e elementos da natureza, procissões, desfiles e paradas, entre outros, são exemplos correntes de formas simbólicas espaciais (CORREA, 2007, p. $8)$.

Cumpre mencionar que o conceito de formas simbólicas espaciais emprega a dimensão geográfica ao fenômeno em tela e, assim sendo, "a relação entre formas simbólicas e espaço são complexas, de mão dupla. Como tal, as formas simbólicas espaciais se realizam, em grande parte, em razão da localização ou do itinerário que cada uma apresenta” (CORRÊA, 2018, p. 227). Nesse sentido, a partir de sua localização, essas edificações ganham sua geograficidade tornando-se geossímbolos (BONNEMAISON, 2002). Centrando-se na questão locacional aludida por Corrêa (2018), o autor aponta que os geossímbolos apresentam uma dimensão relativa e relacional. Considerando a Sinagoga e o Cemitério, essas formas simbólicas espaciais possuem notáveis distinções entre si.

A figura 4 expõe a centralidade da localização da Sinagoga construída pela comunidade hebraica. Edificada acerca de 220 metros do "marco zero" do então distrito iguaçuano, o templo judaico exprime sua condição de localização relativa, a qual, segundo Corrêa (2007, p. 9), associa-se “à visibilidade, mas, sobretudo, à acessibilidade face a toda a cidade ou espaço regional ou nacional". Com efeito, a escolha espacial da Sinagoga considerou sua visibilidade e acessibilidade para a sociedade local.

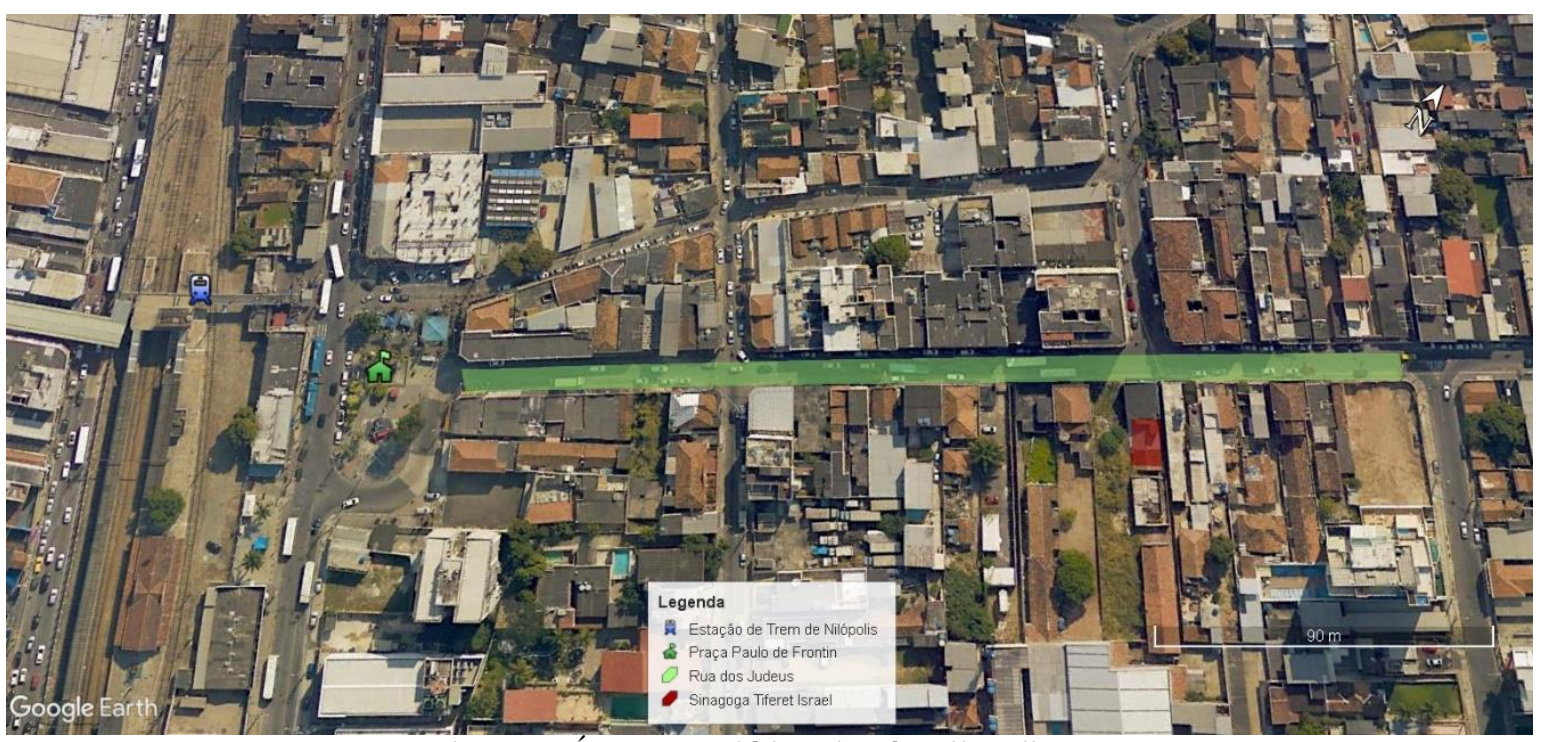

Figura 4: Área central histórica de Nilópolis.

Fonte: Elaborado pelos autores a partir do site Google Earth. 
Conforme mencionado, a parada de trem inaugurada em 1914 ajudou sobremaneira o processo de adensamento populacional da localidade ao gestar, em seu entorno, o núcleo comercial da cidade. Por essa razão, os judeus que chegaram a Nilópolis na segunda metade da década de 1920 se instalaram na incipiente área central da localidade e, com suas atividades, ajudaram a fortalecer a centralidade das ruas locais. Com essa localização, os hebreus marcaram na paisagem nilopolitana sua identidade e, para esse propósito, a acessibilidade do local de culto consiste em "um dos meios mais importantes para que as formas simbólicas possam transmitir as mensagens que delas se espera” (CORRÊA, 2007, p. 9). Corrêa (2018, p. 228-229) menciona ainda que os geossímbolos

\begin{abstract}
apresentam uma localização de natureza relacional, isto é, a localização delas se faz, de um lado, em áreas da cidade dotadas de certos atributos sociais e políticos, visando à emissão de mensagens dirigidas para certos grupos sociais. De outro lado, a localização se dá em relação a outras formas simbólicas localizadas em outros locais e que refletem interesses semelhantes ou divergentes. A natureza relacional da localização associa-se à prática da repetição em locais distintos, de formas simbólicas emitindo mensagens semelhantes, ou em prática de constratação, com formas simbólicas emitindo mensagens antagônicas e situadas em locais próximos.
\end{abstract}

A condição relacional das formas simbólicas explica a espacialidade do "Cemitério dos judeus". No contexto nilopolitano, os espaços cemiteriais estão instalados em um bairro periférico, precisamente o bairro do Paiol. Desse modo, o cemitério judeu foi instalado ao lado do cemitério público municipal cristão, conforme atesta a figura 5. Assim, o Cemitério Israelita, enquanto forma simbólica, emite uma mensagem de “interesse semelhante”, assim como alude Corrêa. 


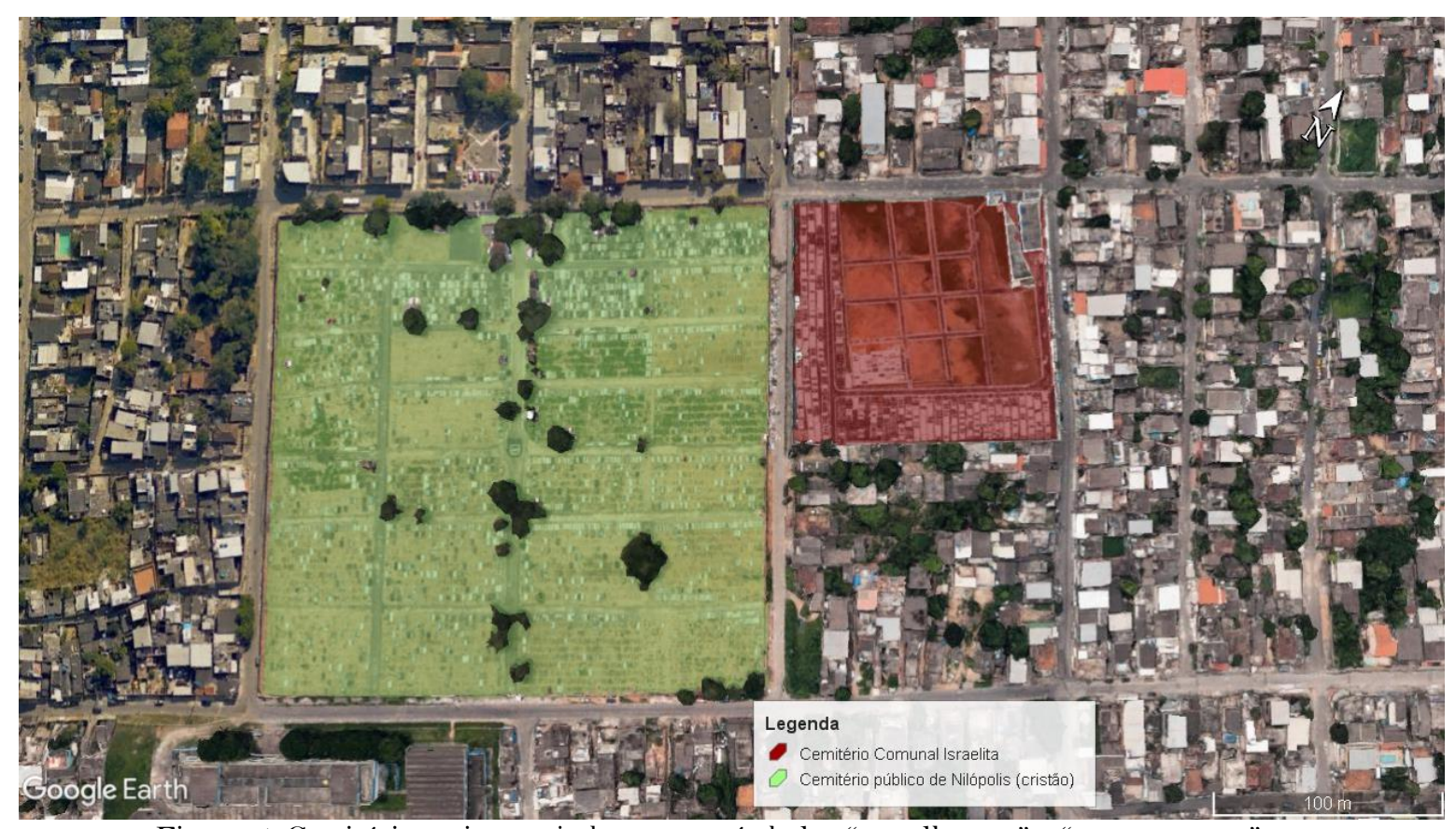

Figura 5: Cemitérios cristão e judeu - geossímbolos "semelhantes" e "constratantes" Fonte: Elaborado pelos autores a partir do site Google Earth.

O Cemitério judaico exprime sua condição de semelhança em relação ao cristão considerando sua espacialidade e sua temporalidade: a necrópole cristã foi inaugurada em 12 de novembro de 1932, e a judaica iniciou suas obras em 17 dezembro de 1933 (CARDOSO, 1938). Ao mesmo tempo, o geossímbolo hebraico reafirma uma forma simbólica espacial “divergente”, pois, conforme sustenta Figueiredo (2019, p. 156), “o cemitério reflete os costumes funerários, mentalidades a respeito da morte, valores, identidades, religiosidade, estilo arquitetônico e memória das comunidades que os criaram".

Na cidade do Rio de Janeiro no início do século XX existiam cinco necrópoles nas quais os israelitas poderiam ser sepultados. Os Cemitérios dos Ingleses (Santo Cristo), o do Catumbi, o São João Batista (Botafogo), o de São Francisco Xavier (Caju) no qual foi criada uma quadra para "não católicos" - e o de Inhaúma - primeiro destinado exclusivamente para sepultamento de mulheres judias e denominado de "cemitério das polacas”, em referência ao fato de ter sido fundado a partir de uma instituição criada por mulheres judias rejeitadas pela comunidade israelita por exercerem a prostituição. Até 1916 as "polacas" eram sepultadas em uma parte separada no São Francisco Xavier (ROITBERG, 2015). Desse modo, 
até 1920 estas eram as opções para enterros judaicos: ao lado das prostitutas e cafetões, figuras tratadas como párias em vida, ou junto de cristãos. Então para os imigrantes europeus as opções existentes eram inaceitáveis e se tornava necessário um cemitério próprio. Tentaram obter um terreno junto à prefeitura do Rio de Janeiro, que respondeu negativamente, declarando que já existia um cemitério judaico municipal, o de Inhaúma (ROITBERG, 2015, s.p).

Diante desse impasse com a prefeitura do Rio de Janeiro, um segmento da comunidade judaica adquiriu em 1920 um terreno no bairro de Vila Rosali, atualmente pertencente ao município de São de Meriti na Baixada Fluminense. A construção desse cemitério é anterior à chegada de judeus em Nilópolis e, dessa forma, diferentemente da necrópole judaica nilopolitana, que foi construída para atender a comunidade hebraica local, o espaço cemiterial da Vila Rosali se destinava aos sepultamentos de judeus sediados na cidade do Rio de Janeiro, uma vez que não havia colônia judaica no referido bairro.

Com efeito do rito diferente no momento da morte, a comunidade judaica em Nilópolis necessitou ter seu próprio espaço cemiterial para atender suas tradições. Por esse motivo, essa forma simbólica espacial exprime uma condição contrastante. A análise comparativa entre os dois geossímbolos retratados na figura 5 indica parte dessas distinções.

A primeira diferença explicitamente notada refere-se às dimensões físicas. A área ocupada pelo cristão corresponde a quatro vezes a área do Cemitério Israelita. Apesar dessa extensão destoante, o adensamento de uso do Cemitério cristão é superior ao verificado na necrópole israelita. Com efeito, toda a área da forma simbólica cristã é usada - onde o solo está exposto, são as chamadas covas rasas. Por outro lado, o espaço judeu ainda está subutilizado, apresentando apenas cerca de um terço da área ocupada pelas sepulturas e, diferentemente da necrópole cristã, os jazigos judaicos nesse cemitério são perpétuos.

Outra distinção entre os espaços cemiteriais diz respeito à espacialização e arquitetura dos jazigos. Figueiredo (2019, p. 150) lembra que

nas sociedades cristãs europeias, desde a idade média os sepultamentos ocorriam no interior das igrejas, em seus pisos ou paredes, nos muros externos ou ao redor do templo (no pátio). Os locais de sepultamentos obedeciam a uma hierarquia, isto é, existiam áreas mais privilegiadas para os sepulcros. Os altares e o vestíbulo da igreja eram destinados aos nobres e às autoridades políticas e eclesiásticas.

Essa hierarquia social pautada na espacialidade aludida pela autora manteve-se com a criação dos cemitérios públicos distantes "do núcleo habitacional da urbe" 
(FIGUEIREDO, 2019, p. 151). O espaço cemiterial cristão apresenta um processo de segregação espacial, pois quanto mais próximas da entrada principal estão as sepulturas mais elevado o seu preço, e também social, aferida pela arquitetura comparativa entre os jazigos. Assim, os cemitérios cristãos refletem a própria segregação e desigualdade das cidades. Nas necrópoles judaicas não há essas distinções, pois as sepulturas apresentam maior uniformidade e simplicidade.

Outra questão destoante entre essas formas simbólicas religiosas no contexto nilopolitano diz respeito à conservação. $\mathrm{O}$ cemitério cristão, apesar de ser o segundo local mais sagrado para essa religião, tem sua fachada, seus muros e a parte interna extremamente mal conservadas pela municipalidade. Em contrapartida, o geossímbolo israelita apresenta-se impecavelmente conservado, possuindo cerca elétrica em seus muros e vigilância patrimonial vinte e quatro horas por dia.

Para Claval (2012, p. 99), "se a geografia cultural se dedica à experiência que os homens têm do mundo, da natureza e da sociedade, ela deve partir daquilo que os seus sentidos lhes revelam”. Partindo desse pressuposto, a necrópole judaica revela um sentido de "distanciamento" entre a população do seu entorno. Essas diferenças, mais que uma distinção imaterial sugerida pelas questões sagradas associadas a essa forma simbólica, expõe também uma conotação material, pois o Cemitério Comunal Israelita destoa da infraestrutura das imediações, seja pela ostensividade de sua segurança, seja pelo impecável estado de conservação de sua edificação, a qual está instalada em um dos setores censitários de menor renda domiciliar média do município, de acordo com o Censo Demográfico do IBGE de 2010.

Assim sendo, devido à sua imponência relativa, o Cemitério judaico comunica, em alguma medida, uma espécie de "enclave" aos moradores locais, tanto assim que para alguns residentes o critério diferencial entre os dois espaços cemiteriais é o social e não o religioso. As duas formas simbólicas, judaica e cristã, respectivamente, são popularmente alcunhadas como cemitério dos ricos ou dos gringos e cemitério dos pobres.

\section{Para não concluir}

Considerando os imigrantes que aportaram no município nilopolitano, embora os libaneses tenham vindo em menor número - apenas duas famílias, os Abraão David e os Sessim David -, esse grupo étnico deixou registros mais notórios na paisagem da 
cidade do que a colônia judaica. Essa constatação deriva do fato de eles terem se entranhado na política e terem permanecido em Nilópolis após obterem ascensão econômica. Para efeito de comparação, de acordo com Albuquerque e Ribeiro (2018), na municipalidade existem onze logradouros públicos em homenagem a personalidades de origem libanesa e apenas dois em referência a judeus que viveram na cidade: a escola pública de artes plásticas Fayga Ostrower e a rua Júlio Berkowitz, proprietário da gráfica onde foi impresso o primeiro jornal local.

Em que pese essas homenagens e o fato de algumas residências da "rua dos judeus" manterem em sua fachada a estrela de Davi, a cultura judaica agoniza na memória da população local. O território cultural nilopolitano é notadamente marcado pela presença da Escola de Samba Beija-Flor no campo profano e pela massiva presença cristã (evangélica e católica) no campo do sagrado. Territorialidades simbólicas robustas que "sufocam" identidades culturais pretéritas, concorrendo para o apagamento das contribuições semitas para a localidade.

A esse quadro de âmbito simbólico se somam a inoperância da administração municipal e a indiferença da própria comunidade judaica em relação ao estado precário de conservação da Sinagoga. Considerando a necrópole judaica, o Cemitério nilopolitano provavelmente não se configura hodiernamente como a primeira opção para as famílias israelitas mais abastadas e, por essa razão, os judeus sepultados em Nilópolis correspondem, em última instância, àqueles que os ascendentes tiveram alguma relação com a comunidade local ou àqueles que não possuem jazigos próprios em Cemitérios da cidade do Rio de Janeiro e no de Vila Rosali.

Tal fato sugere que, assim como a Sinagoga nilopolitana, a necrópole judaica é preterida por essa comunidade. Todavia, uma vez que a Sinagoga encerrou suas atividades na década de 1980, apelando a um jogo semântico contraditório, é na forma simbólica espacial reservada à morte que a tradição judaica permanece viva em Nilópolis na conjuntura atual.

\section{Agradecimentos}

Gostaríamos de agradecer o convite para participar deste número especial da Revista Espaço e Cultura e parabenizar a professora Zeny Rosendahl, responsável pelos 25 anos da criação deste importante periódico. 


\section{Referências bibliográficas}

ALBUQUERQUE, Enderson. De povoado a município: transformações socioeconômicas em Nilópolis. In: MARAFON, Gláucio; RIBEIRO, Miguel Angelo (orgs.). Revisitando o território fluminense. Rio de Janeiro, Eduerj, 2017, pp. 189-208.

ALBUQUERQUE, Enderson; RIBEIRO, Miguel Angelo. Apropriações simbólicas dos espaços públicos: territorializações por meio de toponímias em Nilópolis. E-metropolis, v. 9, n. 35, dez. de 2018. pp.7-16.

BONNEMAISON, Joel. Viagem em Torno do Território. In: CORREAA, Roberto Lobato; ROSENDAHL, Zeni. (Org.). Geografia Cultural. Rio de Janeiro: Editora UERJ, 2002.

CARDOSO, Ernesto. Nilópolis de Hontem e de Hoje. Nilópolis: L \& J. Berkowitz, 1938.

CLAVAL, Paul. As abordagens da geografia cultural. In: CASTRO, Iná Elias de; GOMES, Paulo César da Costa; CORRÊA, Roberto Lobato (orgs.). Explorações Geográficas: percursos no fim do século. Rio de Janeiro: Bertrand Brasil, 2012. pp. 89-117.

CORRÊA, Roberto Lobato. Formas simbólicas e espaço - algumas considerações. Revista GEOgraphia. Ano 9, n. 7, 2007.

. Caminhos paralelos e entrecruzados. São Paulo: Editora Unesp, 2018.

EARP, Fábio; FRIDMAN, Fania. Crédito e cartões, os ambulantes judeus no Rio de Janeiro. Revista História econômica Ė história de empresas. v.2, 2003. pp. 57-73

FIGUEIREDO, Olga Maíra. Turismo e lazer em cemitérios: algumas considerações iniciais. In.: RIBEIRO Miguel Angelo; FERNANDES, Ulisses da Silva (orgs.). Geografia e turismo: reflexões interdisciplinares. Curitiba: Appris, 2019. pp. 149-162

LONDON, Esther. Vivência judaica em Nilópolis. Rio de Janeiro: Imago, 1999.

MACIEL, Caio. Espaços públicos e geo-simbolismos na "cidade-estuário": rios, pontes e paisagens do recife. Revista de Geografia (Recife) V. 22, No 1, 2015.

NOGUEIRA, Marcus Antonio Monteiro. Memorial Nilopolitano. Nilópolis: Prefeitura de Nilópolis, 2009.

OLIVEIRA, Rafael da Silva. Da produção de laranjas à febre dos loteamentos: as transformações na organização espacial do município de Nova Iguaçu ao longo do século XX. Revista Pilares da História, 2011, v. 10, n 11, pp. 33-45.

PERES, Guilherme. O Processo de Urbanização: a Estrada de Ferro D. Pedro II. In: TORRES, Gênesis (org). A Contribuição de Uma História. São João de Meriti-RJ: IPAHB, 2004.

— Nilópolis, Seu Povo, Sua História. Diário Fluminense. Nilópolis, nov.2010/mar. 2011. pp. 95-99.

Presença judaica na Baixada Fluminense. Revista Pilares da História, 2015, v. 14, n 15,

RAPOSO, Fernanda Capri. Nilópolis judaica: de cidade imaginada à tradição inventada. Revista Periferia educação, cultura e comunicação. v.6 n.1 jan-jun, 2014. 
RIBEIRO, Paula. Cultura, memória e vida urbana: judeus na Praça Onze, no Rio de Janeiro (19201980). 2008. 289f. Tese (Doutorado em História Social). Pontifícia Universidade Católica de São Paulo, São Paulo, 2008.

ROITBERG, José. História do Cemitério Israelita da Vila Rosali - O Rio Judeu que o Povo Esqueceu. Roitblog [on line]: Rio de Janeiró, 2015. Acesso em 05 de jul. 2020. Disponível em httproitblog.blogspot.com/2015/07/historia-do-cemiterio-israelita-da-vila.html

SOARES, Hebert Quaresma. Sinagoga Abandonada: história, etnicidade e identidade judaica em Nilópolis - RJ. 2014. 109f. Dissertação (Mestrado em Ciências da Religião). Universidade Presbiteriana Mackenzie, São Paulo.

SEGADAS SOARES, Maria Therezinha de. Nova Iguaçu: absorção de uma célula urbana pelo grande Rio de Janeiro. Revista brasileira de Geografia. Rio de Janeiro, Ano 24, No 2, pp.157-241, Abr/jun. 1962.

SIMÕES, Manoel Ricardo. Da Grande Iguaçu a Baixada Fluminense: a emancipação política e reestruturação espacial. In: OLIVEIRA, Rafael da Silva (org). Baixada Fluminense: Novos estudos e desafios. Rio de Janeiro: Paradigma Editora, 2004.

- A Cidade Estilhaçada: Reestruturação Econômica e Emancipações Municipais na Baixada Fluminense. Mesquita-RJ: Entorno, 2008.

VIEIRA, Radamés. Novos Lares - Judeu em Nilópolis. Documentário. ProSol Produções Audiovisuais. Rio de Janeiro, 2009. Disponível em https://www.youtube.com/watch?v=Mc8bBlHRfS8\&t=7s. Acesso em 21 de junho de 2020. 